\title{
Analytical Chemistry in the Russian Federation (1991-2010)
}

DOI: $10.1134 / \mathrm{S} 1061934811110189$

The first twenty years of existence of the largest fragment of the disintegrated Soviet Union were rather difficult, especially the 1990s. The drastic reduction in support to science and education and the collapse of industry led to salary cuts for those working in science and education, obsolescence of equipment, deterioration of the information service, and other negative effects. This, in turn, resulted in a considerable brain drain, a drop in prestige of scientific work and teaching, and a decrease in the inflow of young people to these fields. The backbone of science to a significant degree was veterans, people of the older generation. Now the situation is improving, but the development of science and education is hindered by endless reforms, which are quite often ill-conceived, hasty, ambiguously targeted, and sometimes simply harmful.

Nevertheless, in Russia much has been done in analytical chemistry in these years. Unfortunately, the decline in world interest in Russian science has resulted in poor knowledge of our achievements worldwide. Therefore, certain steps are necessary aimed at how to best inform foreign colleagues about the most important and interesting results obtained by Russian researchers: publications in international journals, presentations at prestigious conferences, publication of our books in English, etc.
The editorial board of Zhurnal Analiticheskoi Khimii decided to solicit a series of papers describing Russian works in a number of branches of analytical chemistry. Unfortunately, not all of the solicited reviews have been written; therefore, some of important directions are yet uncovered. The received papers are presented in this issue.

I would like to say some things about the directions not considered in this series of reviews.

Studies performed in chromatographic analysis are noteworthy, especially in liquid chromatography. Good liquid chromatographs are produced, including those using an original amperometric detector. New stationary and mobile phases have been proposed. Numerous useful procedures have been developed on the basis of liquid chromatography for analyzing medicines, biological fluids, samples of space activity, and, of course, environmental samples.

In the field of atomic emission spectrometry, we note a data-processing and other systems developed and widely introduced by the VMK Optoelectronics Corporation (Novosibirsk). 